\title{
Students' Perceptions of Using Collaborative Learning as a Tool for Acquiring Writing Skills in University
}

\author{
Daljeet Singh Sedhu ${ }^{1,2, *}$, S. Chee Choy ${ }^{1,2}$, Mun Yee Lee ${ }^{1,2,}$ \\ ${ }^{1}$ Research Centre for Educational Psychology and Instructional Strategies, Kampar, Malaysia \\ ${ }^{2}$ Tunku Abdul Rahman University College, Perak Branch Campus, Kampar, Malaysia
}

Email address:

daljeetsingh@mail.tarc.edu.my (D. S. Sedhu), choysc@mail.tarc.edu.my (S. C. Choy), leemy@mail.tarc.edu.my (M. Y. Lee)

To cite this article:

Daljeet Singh Sedhu, S. Chee Choy, Mun Yee Lee. Students' Perceptions of Using Collaborative Learning as a Tool for Acquiring Writing Skills in University. American Journal of Applied Psychology. Special Issue: Psychology of University Students.

Vol. 4, No. 3-1, 2015, pp. 1-6. doi: 10.11648/j.ajap.s.2015040301.11

\begin{abstract}
This paper examines students' perceptions of the use of group discussion as a collaborative learning tool among English-as-a-Second-language (ESL) learners when learning writing skills in university. Studies on collaborative learning have shown that group discussions enhance students' learning experiences and knowledge. Collaborative learning in the form of group discussions has encourages students to produce work that is creative as well as stimulate critical thinking. This form of learning further develops interpersonal skills and social relationships among students. Twenty-four university students divided into six groups were the respondents in this study. The data was collected using voice recorded transcriptions of a semi-structured interview session with each group after completing the collaborative learning activity. The transcriptions were then analysed qualitatively using the interpretative approach. The transcripts were read and reread until common ideas emerged that were then categorised and discussed under various themes. The results showed that students perceived that collaborative learning tended to help them reflect on the content and context of the tasks they had to carry out. This form of learning was perceived to increase their confidence and motivation to communicate with their peers in a second language, and there were higher rates of task completion.
\end{abstract}

Keywords: Students' Perceptions, Group Discussion, Collaborative Learning

\section{Introduction}

There is research evidence to show that using group work can effectively enhance the learning experience of students in the classroom [1,2]. Group work is looked upon favourably by educators, as it can enhance creativity and critical thinking, build stronger interpersonal skills, and enhance relationships with the faculty. However, students may not share the same views as educators. It has been found that students are not able to manage the amount of time and work needed to effectively carry out group work [2]. Hence, for collaborative learning to be an effective and positive experience for students, it is necessary for teachers to brief their students to prepare them when using this method. Barcelona and Rockey [1] noted that it is important to take into consideration the type of task, the group organisation, and type of evaluation involved. Some teachers do not use collaborative learning or are not in favour of this form of learning because they find controlling the class difficult. Further to this, the course content may also limit its use and there is concern by teachers of the timely completion of the course syllabi in order to meet key performance indexes [2].

\section{Students' Perceptions and Collaborative Learning}

According to Haber [3] collaborative learning became popular as a tool when it was found to help students who are inadequately prepared for college level courses. This form of learning is also appropriate for students who respond well to classroom group work. It has a distinct advantage over the teacher centred approach in that it allows students to interact with the content materials from their own context and to share their views with others in their group. Apart from this, the idea behind the use of collaborative learning when teaching writing skills is to provide students with hands on as well as real life experiences of working as part of a team. Haber emphasises that in many professions writing is often carried out in teams, 
and the ability of individuals to participate in such activities is crucial for their success in the work place [3]. As such, he suggests a five point-plan to carry out this activity: have students work in groups to write well organised paragraphs together; have them discuss their work in the group and generate a set of possible questions that could be asked about their work. Then, using the work they have generated, these students will lead a class discussion and finally write a summary of the discussion.

Using group work as a tool to enhance students' learning has its problems especially when attempting to give a fair assessment for each member in the group. High achievers and low achievers participate differently, with high achievers working harder than average while the low achievers participate only minimally. Hence, when assessing students in such tasks, half of the assessment will focus on group work while the other half will be on individual effort. Added to this, each member must also be assessed on their oral participation in the group [3], adding to the overall challenges when using collaborative learning.

In another study on this form of learning in the classroom, Kuech [4] found that it can promote critical thinking and reflection among students as well as inter-subjectivity where students use their knowledge of other subjects in their conversations to help them learn. This finding provides evidence that student-to-student interaction or peer social interaction helps with developing higher order thinking of concepts being learned.

\subsection{Quality of peer interactions}

Several studies, [3, 4] have shown that certain types of peer social interactions have been beneficial to learning, specifically for the motivational and social-cognitive interactions. Starmaan et al [5] also found learning environments that involved face-to-face peer social interactions effectively brought about learning. When compared to more traditional instructional settings where students are expected to learn individually, exchange of ideas, information and opinions does not occur very frequently. Hence, in peer social interaction situations, learning is allowed to occur in a collective participatory process of active knowledge construction [6]. Such interaction will allow students to discuss and develop ideas and perceptions that could otherwise be sidelined or ignored in an individual learning setting.

Often, peer interactions that are meaningful will lead to rich opportunities for learning cooperation, gaining support and developing interpersonal skills [7]. According to Wentzel and Watkins [8], peers have the potential to provide contexts of learning that can have a profound impact on students' academic performance. Further to this, the social support by peers and feelings of belongingness can motivate students to engage in learning activities and to display socially appropriate forms of behaviour. Apart from peer interaction, the perceptions of students towards the content and context of the material would also influence how well they learn.

\subsection{Student Perceptions}

Perceptions, according Ajzen et al [9], will determine how an individual's motivation is influenced by how difficult learning something is perceived to be, as well as how successfully the individual can or cannot perform the activity. If the individual holds strong beliefs of the existence of factors that will facilitate a behaviour, in this case collaborative learning, then the individual will have high perceived control over the activity. Conversely, a low perception of control will impede the learning activity. An individual's perception can be influence by factors like past experiences, anticipation of an upcoming event or situation, and the attitudes that the individual hold.

Ajzen [10] suggested in his principle of compatibility that there will be a strong attitude-behaviour correlation if the expected behaviour and the attitude that precipitates that behaviour involve the same action, target at which the action is aimed, the context in which it occurs, and its time of occurrence. Hence, the perceptions of an individual can, to a certain extent, predict his or her behaviour as it is a precursor for forming attitudes. When applied to a collaborative learning situation, the teacher must be actively involved in transmitting the intent of the activity to the students who can then demonstrate this intent through their actions during the activity itself. This intent and perceptions of the students will also determine how hard they are willing to try and the effort they will exert during the learning activity in order to bring about a successful outcome. The success or failure of the activity is influenced by three components: the students' perceptions and attitudes toward collaborative learning, the perceived social pressure in the group, and the perceived control students have over their actions.

The current study will attempt to determine students' perception of the effectiveness of collaborative learning among students learning writing skills in an ESL course in a university in Malaysia through their perceptions of the learning experience. It will also consider the influence of instructions given by the teacher on the intentions and perceptions among students when learning such skills.

\section{Methodology}

A qualitative approach, namely the interpretive approach, will be used because this study is interested in empowering individuals by giving a voice to their perceptions of a learning activity. The intention is not to over simplify the voices of the individual [11] by summarising their concerns but to develop them further to an interpretative level. This approach will entail, firstly a highly intensive and detailed analysis of accounts produced by the participants which will be captured verbatim. Secondly, to provide a critical and conceptual commentary on the participants' 'sense-making' activities.

The view of social constructivism [12] will be used in the interpretive approach for this study. The perceptions of and comments by the participants of the learning situation will be 
highly valued as it is formed through interactions with others and also through the historical and cultural norms that operate in the lives of the participants. In order to achieve this, the questions asked during the interviews with the participants will be broad and general so that they can construct their own meaning of the situation.

\subsection{Student Sample}

The sample used in this study was a convenience sample of twenty-four students in an ESL course in a Malaysian university. A convenience sample was used to avoid disrupting class groupings that had been prearranged at the beginning of the semester. The student sample belonged to a class that was picked from the three ESL class groupings taught by one of the co-researchers. There were thirteen females and twelve males between the ages of eighteen and twenty-one in the class. They were all full time students enrolled in the various diploma programmes offered by the university. These students consented to take part in the study and were told that any information they provided would be kept confidential and viewed only by the researchers. They were allowed to withdraw from the study at any time if they wished.

\subsection{Design and Procedure}

The twenty-four students were divided into six groups of four. They were named Group A, Group B, Group C, Group D, Group E and Group F. The students were to collaboratively write letters of enquiry. In order to gain insight into their perceptions and intentions on collaborative learning, each group was interviewed after the activity. This was to provide a way to analyse how these students interacted while they were in a group to produce the content for the letters. The topic of writing a letter of inquiry was taught for three weeks of the fourteen-week ESL course. This consisted of three ninety-minute lessons.

All the students were briefed during the first lesson by the teacher on the activities that will occur in the next two lessons. They were then divided into their groups and each group was instructed to choose a leader. The role of the leader was to assign tasks to be carried out by each group member. The teacher then briefed them on the goals of the activities to be carried out.

The first goal was for each student to produce two letters of inquiry, one asking for accommodations and the second to apply for a job vacancy. A brief prepared by the teacher containing all the requirements of the letters was provided to each student. The brief also contained the format of the letter for easy reference. The second goal was for each group to produce a letter of enquiry to organize a charity event of their choice. Each group was given a list of items to be included in the letter. They were instructed to discuss the content and context of the letter and produce it in the correct format. The role of the group leader was to ensure that the tasks were distributed to each member, so that all of them would participate equally in completing the tasks.
After the three lessons each group was interviewed with the intention of determining their perceptions of the collaborative learning process. The questions were broad and open-ended to allow students to express their perceptions of the letter writing experience during the interview. Each student was encouraged to express their perceptions of the learning experience and they were asked to elaborate on points that needed further clarification where necessary.

The taped interviews were then transcribed so that the scripts could be analysed using the process of topic ordering [12], a term used to describe the process of preparing qualitative data for analysis. The transcripts were analysed inductively and the main categories were allowed to emerge from the data through repeated readings. They were then read a number of times in order for the categories to become more evident. The final categorization of the data was checked by a co-researcher for consistency.

\subsection{Research Questions}

In Malaysia students learn English as a second language and it is considered an important language to master for their future careers. The current study is interested in determining students' perceptions of the efficacy of using collaborative learning in the form of group discussions to help ESL students learn letter writing skills. There is a dearth of research into the use of this form of learning to facilitate acquisition of letter writing skills. The research questions (RQ) underpinning this study are:

RQ1. What are students' perceptions of the use of group discussions when learning to write in a professional context?

RQ2. How did the collaborative learning experience help students in their overall perceptions of learning ESL?

\section{Results}

RQ1. What are students' perceptions of the use of group discussions when learning to write professionally?

The transcripts of the interviews and discussions were analysed and the following themes emerged from the data. They are: increased clarity and focus on assigned task, effective and efficient team learning, and better time management. In an attempt to make the quotes from students more understandable the language used was corrected.

\subsection{Increased Clarity and Focus on Assigned Task}

The group discussions allowed students to get more clarity and focus on the tasks they had to perform. They perceived they had better comprehension of the content and context needed for the letter writing exercise. For instance, students in Group C explained:

\footnotetext{
"Before we proceed further in doing anything, my group members and I analysed the questions given to us. After that we discussed among ourselves how to answer the question given. We will read and understand the requirement of the question first and we made sure that each of our group members is able to get a clear picture of what
} 
the question required".

\subsection{Effective and Efficient Team Learning}

Each student was assigned to write a letter of enquiry with the support of their group members. Each member in the group had to pick a task from a list ranging from formatting of the letter to editing each letter produced by the group. The group leaders perceived they were able to efficiently and effectively assign tasks to each member resulting in better cooperation and team work. For instance, one student of Group A said:

"We divided up the job writing the letter of enquiry. Each one of us had a different duty, two persons will prepare the points for the content, another person will prepare format of the letter, and one will do the final write-up and editing. The job was divided by our group leader. We had good team work."

\subsection{Better time management}

Students were able to complete all the tasks given to them in the allowed time. Added to this, they were able to edit all the letters that were written before they were handed in. The students perceived they were more focused and managed their time well with support from the group. All the letters produced were according to the format described in the brief with contents that were reflective of a letter of enquiry. For instance, students in Group C said:

"We managed to write-up the letter of enquiry in thirty minutes out of the forty minutes given to us by our lecturer. It is much faster to complete the work given to us using this way than doing it individually. My lecturer then summarized the whole process at the end of class"

\subsection{Discussion}

It would seem from students' comments that if they were given the opportunity to discuss a writing task before carrying it out, they could complete it with better results. They had better comprehension of what they had to do after discussing with other members of their groups. This supports research that suggest group discussion can enhance creativity and support critical thinking among students when they are given a task to complete $[1,2,4]$.

Students perceived they were more focused on completing the tasks assigned by their leader. Contrary to the findings by Haber [3], each of these students were required to complete a letter of inquiry, hence they were exposed to the whole process of writing a letter of enquiry. Further to this, they showed interest and were intent on completing their tasks. As further reinforcement of the learning that had taken place, the teacher gave an overall summary of the letter writing process at the end of the lesson. These students were also given numerous opportunities to hone and reinforce their writing skills by having to write three different forms of inquiry letters.

The students were able to complete the tasks within the time allotted. They perceived that group discussions helped them complete the task faster than if they had done it on their own. This does not support the findings of Barcelona and Rockey [4] that students do not manage to complete a given task adequately in a given time period during group work. It would seem that with proper instructions and guidance from the teacher, students were very capable of completing assigned tasks. Hence, it is important for teachers to consider the types of learning experiences presented to students and the resource materials used to enhance collaborative learning experiences [2].

RQ2. How did the collaborative learning experience help students in their overall perceptions of learning ESL?

The data was analysed, and common themes were allowed to emerge which were used to answer RQ2. These themes were: improvements when communicating using English, able to identify mistakes in letters written by group members, and rote memorization not used

\subsection{Improvements When Communicating Using English}

Students perceived that they could communicate better in English during and after the group discussions. Students with a weaker command of English were able to listen and learn from those with better proficiency as they interacted during the group discussions. At the same time, the weaker ones developed more confidence when communicating in the language. For instance, one student from Group F said:

"I feel my communication skills have improved after I started to interact with my group members who have better language proficiency. I am more confident now. This is because my group members always made sure we communicate using English language."

Through the group discussions, some of them were able to overcome certain fears when communicating in English with their more proficient peers. For instance, a student from Group E said:

"I used to feel shy when speaking or discussing with my course mates who have better English language proficiency than me, but now I find that by discussing with them I can improve my language skills."

\subsection{Able to Identify Mistakes in Letters Written by Group Members}

Students perceived they were able to learn from the mistakes they made using feedback given by other group members during the discussions. Those with a better command of English were able to identify the mistakes of the weaker ones. Hence, through such peer interactions, the weaker students to a certain extent learned about correct grammar and sentence structure. For instance, a student from Group B said:

"When I was writing the letter of enquiry, my group members showed me my mistakes. They also showed me the mistakes in my sentence structure and the grammar errors when I wrote the initial draft of the letter. This 
became a guide for me when I wrote the letter of enquiry on my own."

\section{Another student in Group C said:}

"I could understand my mistakes better in a sentence I had done previously when I went through this group discussion session. I realised the mistakes, and I will take note not to repeat them, as my group members explained to me the correct way of writing a sentence structure and taught me new words that I was unaware of before this."

\subsection{Rote memorization Not Used}

Students perceived that they did not need to memorise a sample letter in order to complete the assigned task. Rote memorisation is a common practice among Malaysian students learning ESL as it is believed to help them to produce better quality work. However, with the use of collaborative learning, the students wrote the letter of enquiry by analysing and brain storming during the discussions on what was needed in the letter based on the brief that was given to them. For instance, a student in Group A said:

"After going through the group discussion session, I realised that I do not need to memorise previous contents when answering a question. Different questions require a different set of answers. I usually memorise the contents of earlier work and use it again on a new task".

\subsection{Discussion}

Students perceived they were able to have better confidence when communicating in English with group members who had a better command of the language. The interactions even helped these students overcome their shyness about communicating in English. This supports research by Ajzen [9, 10] that states the perceptions of individuals towards a task can predict their behaviour. In this case, the students changed their perceptions of the English language and became more confident when communicating with it. This finding supports the use of group discussion as a tool to enhance students' learning but does not support the finding by Haber [4] that high and low achievers were unable to work together in a similar way to complete a given task. However, task completion may also be dependent on the subject matter as well as the context of the task assigned [9, 10]. Students' perceptions of and attitudes towards carrying out an assigned task will determine their behaviour when carrying out the task [10]. This further supports the findings of Barcelona and Rockey [1] that group discussion builds stronger interpersonal relationships among students.

Students perceived improvement when communicating in English and gained confidence when speaking it. They were able to learn from their mistakes, and they were receptive to the feedback given by their peers. This finding supports group discussions as a means of promoting reflection among students on how they produced the results of a given task [4]. During the discussion there were peer social interactions [5] that helped these student better comprehend the task they had to carry out. This supports research by Kuech [4] and Staarman [5].

Students were not using rote memorisation to help them write the letter of enquiry. They used a more reflective and analytical approach to writing the letter by incorporating previous and current knowledge. The group discussions helped them write the letters using their own words rather than using texts that they had memorised or copied from another source. This finding supports research by Haber [3] that when students go through the process of collaborative learning, they are able to incorporate their previous learning with current learning to form new knowledge.

\section{Limitation of Study}

As with any research, this study is not without its limitations. A major limitation is its focus on only one use of collaborative learning to learn writing skills, that is, writing letters of enquiry. Further studies need to be carried out on other aspects of writing, such as essays and other formal written communications to determine if this approach is as efficacious. It would then offer a broader comparison of the efficacy of using collaborative learning to teaching writing and its effectiveness in enhancing students' confidence when communicating in English. It would similarly be interesting to determine if there is a strong attitude-behaviour correlation [10] when a change in students' perceptions and attitudes toward communicating in English is precipitated through collaborative learning and its effects on students' use of English post intervention.

\section{Conclusion}

The findings of this study support the use of collaborative learning to teach writing skills. All the students had positive perceptions of their learning experience. The results suggest that students become more reflective and analytical of the tasks they had to carry out after they were allowed time to discuss with their peers. Peer learning was effective if students were properly briefed by their teachers on the goals of the tasks. The students were focused on completing the tasks they were assigned and linking them contextually to their own learning. They also used the feedback given by group members to assess their own learning.

Added to this, students' comprehension of the tasks they had to carry out seemed to improve after group discussions. They gained clarity and focus from the discussions. The results of this study also shows that collaborative learning builds students' confidence when communicating in English as well as enhance their writing skills. There is, however, no evidence that it improves their overall comprehension of the language.

The social support given by fellow team members also helps students gain confidence about completing the tasks. The students, in general, were receptive to this form of learning and managed the timely completion of the tasks they 
were assigned, which does not support finding by Barcelona and Rockey [1]. However, it must be noted that students' behaviour toward an assigned task might depend on their perceptions of and attitudes towards that task [9].

Students perceived they learned from the comments of their peers. Added to this, they also gained confidence from the learning experience and were less hesitant about communicating in English. However, the duration of this feeling of confidence could not be assessed from this study. The overall collaborative learning experience was positive as all of them managed to complete the tasks they were assigned. This finding did not support research by Nayan, et al, [2], that most teachers perceived collaborative learning resulted in work that was unfinished and students unwilling to carry out tasks. This suggests that a collaborative learning experience must be well planned by the teacher and the students must be given proper briefings about the goals and tasks of the activity. The teacher's facilitation skills in monitoring such a learning experience may well be crucial if the whole experience is to be meaningful. If this form of learning is to promote independent learning among students, monitoring and proper planning by the teacher is crucial. Students new to this form of learning need to be given relevant guidance in order for the activity to be a positive one for them.

\section{References}

[1] R. J, Barcelona, and D. Rockey, Using collaborative learning technologies to facilitate effective group work. Journal of Physical Education, Recreation \& Dance, 2010, 81(4), pp12-55

[2] S.Nayan, L. A. Shafie, M. Mansor, A. Maesin, and N. Osman. The practice of collaborative learning among lecturers in Malaysia. Management Science and Engineering, 2010, 4(2), pp 115-123.
[3] M. W. Haber, Strategies of collaborative writing and intellectual enrichment. The Journalism Educator, 1994, 48(4), pp 47

[4] R. Kuech. Collaborative and interactional processes in an inquiry-based, informal learning environment. The Journal of Classroom Interaction; 2004, 39(1), pp 33-43.

[5] J.K. Staarman, K. Krol, H. van der Meijen. Peer Interaction in Three Collaborative Learning Environments. The Journal of Classroom Interaction;2005, 40(1), pp 29-39

[6] D. N. Perkins and G. Salomon. Are cognitive skills context-bound? Educational Researcher. 18(1), pp 16-25

[7] J. G. Parker, K. H. Rubin, S. A. Erath, J. C. Wojslowowicz, and A. A. Buskirk. Peer relationships, child development, and adjustment: A developmental psychopathology perspective. In C. Dante and D. J. Cohen, Developmental psychopathology, Vol 1: Theory and method. 2006. Wiley and Sons.

[8] K. R. Wentzel and D. E. Watkins. Peer relationships and collaborative learning as contexts for academic enablers. School Psychology Review. 2002, 31(3), pp 366-377

[9] I. Ajzen. C. Czasch and M. G. Flood. From intentions to behavior: Implementation intention, commitment, and conscientiousness. Journal of Applied Social Psychology, 2009, 39(6), pp. 1356-1372.

[10] I Ajzen. Values, attitudes and behaviour. In S. Salzborn, E. Davidov and J. Reineke, Methods, theories and empirical applications in the social sciences. 2012. Springer.

[11] M. Larkin, S. Watts and E. Clifton. Giving voice and making sense in interpretative phenomenological analysis. 2006. Qualitative Research in Psychology. 3, pp 102-120

[12] J. W. Creswell. Qualitative inquiry and research design: Choosing among five approaches. 2013. Sage.

[13] H. A. Radnor. Researching your professional practice: Doing interpretive research in educational settings. 2002. Open University Press. 